\title{
Nasopharyngeal Laryngoscopy
}

National Cancer Institute

\section{Source}

National Cancer Institute. Nasopharyngeal Laryngoscopy. NCI Thesaurus. Code C38074.

Endoscopic examination of the larynx, via the nasopharynx. 